Running head: PUBLISHING ACTION RESEARCH

Publishing Action Research in Counseling Journals

Douglas Guiffrida, Ph.D.

Kathryn Douthit, Ph.D.
Martin Lynch, Ph.D.

Karen Mackie, Ph.D.

\author{
University of Rochester \\ Warner Graduate School of Education and Human Development \\ Dewey Hall Box 270425 \\ Rochester, NY 14627 \\ Douglas.Guiffrida@Rochester.edu
}




\begin{abstract}
The increased use of action research in counseling training and professional publications provides an opportunity to bridge the research/practitioner gap that has plagued the profession for decades. In this article, action research is defined and; special considerations that counselor researchers need to address when designing, conducting, and reporting action research are presented. Suggestions are included throughout the article to assist counseling action researchers in publishing their studies in ACA journals.
\end{abstract}




\section{Publishing Action Research in Counseling Journals}

Research, in its many forms, is an essential tool for the counseling profession. Data generated by counseling research allows practitioners and educators to (a) explore effective interventions for addressing the increasingly complex worlds of our clients (McLeod, 1999; Whiston, 1996); (b) glean evidence of our clinical effectiveness (Lundervold \& Belwood, 2000; Rowell, 2005; King \& Otis, 2004); and (c) generate alternatives to interventions from other disciplines that may be inconsistent with our developmental, ecological, multicultural, and advocacy-based traditions (Guiffrida \& Douthit, 2010). However, despite the accepted importance of research to the profession, there has been a long-standing schism between research and practice in counseling. For decades, authors (Bauman, 2002; Goldman, 1976; Hepner \& Anderson, 1985; Howard, 1984; Kaplan, 2010; Whiston, 1996) have argued that counselor practitioners do not perceive counseling research as central to their work because it has generally failed to address significant issues in the field, is not conducted in real-world settings, or is presented in ways that are too complex or abstract to be applied to counseling practice. As a result of this perceived gap in clinical utility, counselor practitioners tend to not only avoid engaging in their own research, but most fail to even read research journals in their field (Bauman, 2002; McLeod, 1999).

Schön (1995) has attributed this tension between researchers and practitioners in any field as the dilemma of "rigor or relevance" (p. 28). On the one hand, there are the researchers, whom he describes as living on the high ground, who seek to identify research questions that allow for rigorous, research-based methods of inquiry. On the other hand, there are the practitioners, whom he describes as living in the swamps, whose problems are messier and less amenable to 
solutions based upon standard scientific inquiry. Schön asserted that the irony of this situation is that the problems of the swamp are more relevant to practitioners and society in general than the rarefied research agendas from the high ground and that this reality forces researchers into a difficult choice: "Shall he [or she] remain on the high ground where he [or she] can solve relatively unimportant problems according to his [or her] standard of methodological rigor, or shall he [or she] descend to the swamp of important problems where he [or she] cannot be rigorous in any way he [or she] knows how to describe?” (p. 28).

Schön (1995) argued that the solution to the relevance/rigor problem that has continually plagued the social sciences is to bridge the researcher/practitioner gap through more extensive use of action research. Action research, he argued, not only allows practitioners to shape what is studied, but it also forces researchers to understand and utilize practitioners’ tacit ways of knowing. For these same reasons, several counselors (e.g., Guiffrida \& Douthit, 2010; McLeod, 1999; Rowell, 2006; Whiston, 1996) have advocated for the increased proliferation and acceptance of action research in counseling training and journals as a means for improving and enhancing counselor research and practice.

The purpose of this article is to provide practitioners and researchers with practical guidelines for designing, conducting, and publishing action research. We begin by briefly defining action research. Next we provide a broad overview of steps for conducting action research, focusing specifically on the elements of action research that are distinct from the more traditional forms of quantitative and qualitative research. Throughout the article, considerations for publishing action research in counseling journals are provided. 


\section{Defining Action Research}

Action research is defined as any type of research that shifts the control for the study from the academic or professional researcher to the people who have traditionally been considered the subjects of the inquiry (Herr \& Anderson, 2005). It is conducted with as opposed to on practitioners, clients, or other stakeholders. As such, it focuses on issues or problems that are identified by the practitioners or clients themselves and seeks to disseminate results in ways that genuinely inform or empower their practice or their lives (McLeod, 1999).

Action research was first developed by Kurt Lewin, a social psychologist who greatly influenced the field of counseling, particularly in our understandings of human development, group dynamics, and organizational leadership (Adelman, 1993). Lewin was especially concerned with integrating research with practice as a means of instituting social change geared toward raising the esteem of ethnic/racial minority groups. However, although it was not formally termed action research, McLeod (1999) has argued that the field of psychotherapy also has a rich and long-standing tradition of action research of its own dating back to the first psychoanalytic case studies conducted by Freud and his colleagues.

Action research is an umbrella term that can include a number of similar, yet unique methodologies, including practitioner research, participatory action research (PAR), action science, collaborative action research, cooperative inquiry, educative research, appreciative inquiry, emancipatory praxis, community-based participatory research, participatory rural appraisal, teacher research, and feminist action research (Anderson \& Herr, 2005). Although all share the fundamental tenet of stakeholder authority, each of these variations has grown from different contexts and reflects varying epistemological ideas and purposes. It is beyond the scope of this paper to illuminate all the distinguishing features of each unique approach. However, it is 
important to note that action research is broader than practitioner-research because it does not insist that the practitioner be the main researcher; only that the practitioner is included as a collaborator in the study.

Although action research has been used widely in fields that range from business to social justice/advocacy groups, it tends to be used most widely in helping professions such as education and nursing (Herr \& Anderson, 2005). McLeod (1999) has argued that the approach is especially well-suited to counselors because it utilizes a number of skills inherent in the counseling process, including "reflexivity, collaborative sense-making, and finding meaning in feeling” (p.20).

The erroneous assumption is often made that action research is yet another tradition in qualitative research, adding to genres such as phenomenology, ethnography, and grounded theory. Although the type of self-reflexive exploration that is the hallmark of action research is particularly well served by qualitative methods, action research is not tied directly to any particular method of qualitative data collection or analysis, nor does it preclude the use of quantitative methods. Rather, action research utilizes methodological pluralism, which allows researchers to choose the most pragmatic method (quantitative, qualitative, or mixed) that best suits their particular research question.

Although action research is distinguished by utilizing a variety of research methods and involving participants in the research process, it deviates from the more traditional forms of qualitative and quantitative research approaches in a number of other ways. First, although the results of action research can often be useful to people in similar settings who are dealing with the same types of issues, the intent of action research is not to seek knowledge that is generalizable; rather, action research seeks to generate knowledge in-context for each unique 
setting in which it is instituted (McLeod, 1999). Second, unlike traditional experimental quantitative research, which is often conducted in laboratories or in vitro settings to control for and isolate variables, action research, by definition, is always conducted in real-world or in vivo settings. Third, rather than seeking to avoid intervening in the lives of the participants like most forms of quantitative and qualitative research, action research deliberately provides some type of intervention that seeks to improve the lives of the participants, often through systemic change or advocacy (Herr \& Anderson, 2005).

\section{Steps for Conducting Action Research}

Action researchers often follow the same steps used to conduct standard research; therefore, readers should consult the other articles in this special edition that provide guidelines for publishing various forms of counseling research. There are, however, special considerations unique to action research that must be addressed. The following steps and considerations for conducting action research are drawn primarily from Whiston (1996), McLeod's (1999) book on Practitioner Research in Counselling, Stringer's (2007) book on Action Research in Education, and the authors' collective experience in conducting action research and supervising action research doctoral dissertations. Readers should consult these original works for more detailed descriptions of action research processes.

\section{Step 1: Identify a Problem or Research Question}

As noted earlier, the hallmark of action research is that the problems that are the focus of the research are framed by the practitioners themselves. Therefore, an appropriate research question for a counselor would typically be determined by, or in consultation with, the counselors and/or clients from a particular school, agency, or other community setting. Due to the increased need for outcome based assessment, combined with the growing number of 
practitioners who are pursuing doctoral degrees in counseling, it is often the practitioners themselves who formulate these questions to improve their own practice and/or to earn their doctorates. However, in cases where an academic researcher is leading the research group, the question needs to be discussed in detail with the practitioners, clients, or other stakeholders to fully understand their perspectives.

According to Whiston (1996), the outcome-based questions that counseling practitioners need answered tend to fit into one of three categories: (a) Is what we are doing effective? (b) If so, what aspects of what we are doing are effective? (c) How can we enhance what we are already doing? In addition to providing practitioners with outcome-based assessments, Bogdan and Biklen (2007) have also asserted that action research can focus on highlighting social injustices in efforts to initiate societal change. In such studies, researchers report the perspectives or experiences of clients from marginalized groups in an effort to advocate for alternative or increased services or to change public perceptions regarding members of these groups. The centrality of the social justice agenda in the counseling profession is particularly well served through participatory action research (PAR), an emancipatory form of action research that has as its aim critical reflection and a concomitant understanding of how social realities and understandings are constrained by systems of power (Kidd \& Kral, 2005).

As noted by McLeod (1999), many action research questions tend to begin by addressing issues that may be too broad or complex to be studied effectively in limited time periods (e.g., Is cognitive behavioral therapy the most effective intervention for clients with eating disorders?). Action researchers need to carefully narrow their questions so that they can be explored and understood in their allotted time frames and with their available resources. An example of how the previous question could be narrowed to one that might be more manageable for practitioners 
is the following: What counselor actions do clients with eating disorders perceive as effective during a brief, cognitive behavioral therapy group? That act of guiding stakeholders in the process of formulating manageable questions is a good example of how an academic researcher can collaborate with members of a community of inquirers in a manner that respects the authority of the research participants. Ultimately, the questions need to be based on a combination of what is needed to more effectively serve clients, is of interest to the researchers, and is reasonable to investigate given the available context and resources.

Another important component in selecting a question for action research is to critically review the literature on the topic or population to be studied. In some cases, prior research conducted in this area may be helpful in formulating or narrowing the research question. What makes the literature review a critical review is that the researcher is actively seeking to find gaps in the literature. This gap may be that no studies have been conducted using the new intervention the researcher is examining. Other times there may be numerous empirical studies documenting success with a particular approach but no studies that have examined it with the particular population of interest or that have provided the intervention in the proposed manner. Again, scaffolding stakeholders' assimilation of the body of literature and introducing them to the notion of a critical review can provide a role for the expert academic researcher that does not violate the privileging of participant's self-knowledge.

\section{Step 2: Formulating the Research Design}

Once an appropriate research question is selected, the next task is to formulate the research design. Bogdan and Biklen (2007) have noted that while rigorous methods are important for all research, they are especially important for action research because the results can often challenge established paradigms. For example, action research that highlights certain 
limitations or side-effects of an established course of treatment or psychotropic medication could pose a financial challenge to companies that promulgate the particular approach or medication. This type of study, therefore, is more likely than some others to face intensive scrutiny from stakeholders from the established hierarchies. Additionally, because action research often involves researchers from outside the established research circles who have not attained advanced degrees, these studies can be easier to dismiss than studies generated from teams consisting of all professionally trained, doctoral-level researchers. For these reasons, it is crucial for action researchers to develop studies using methodologically rigorous forms of inquiry. It should be noted that action research need not follow identical paths of traditional quantitative or qualitative research to maintain its rigor (Thorne, 2008). Rigor is contingent on core methodological principles that can be preserved even if researchers need to deviate, through creative iterations modified to accommodate nontraditional research questions, from more traditional quantitative or qualitative methodologies.

McLeod (1999) has noted that action researchers also need to be more flexible and creative in designing studies than traditional laboratory researchers due to the complexity of real world research. This flexibility in design includes allowing extensive time to discuss research design with the leaders of the school or agency to be studied so that data collection procedures are unobtrusive to the clients and site personnel. It is not uncommon from our experience for practitioners to become resistant to the demands of the data collection process. It is crucial, therefore, that the procedures be designed collaboratively with stakeholders from the research site and for the results of the study to be perceived as mutually beneficial to all parties.

Another consideration in the design of action research is the selection of proper outcome measures. When conducting quantitative research, Whiston (1996) has suggested that action 
researchers seek to use existing measures rather than the researchers creating their own instruments. Designing a valid and reliable instrument is time and labor intensive and requires specialized expertise in measurement and evaluation that most practitioners do not possess. Similarly, action researchers utilizing qualitative methods need to carefully select the data collection procedures (structured interview question, open-ended questions, participant observation, etc) that best address the research question.

Irrespective of the data collection procedures or methods used to analyze data, action researchers need to have methods in place to ensure treatment fidelity. From our experience, it is common for counselors to implement approaches that look different from their espoused theories. Judicious use of training, supervision, and/or treatment manuals as part of the study design will provide a measure of consistency of the treatment interventions and support the rigor of the study.

Although there are no specific ethical guidelines for action research, Whiston (1996) and McLeod (1999) have noted some special ethical considerations of which action researchers in counseling should be mindful when designing studies. First, because the counselors themselves are part of the research study, procedures need to be in place to prevent problems associated with dual roles. Counselors, study team members, school and agency personnel, and the clients themselves need to all agree that it is in the best interest of each client to participate in the study at this time, that clients in no way feel coerced to participate, and that they are free to decline participation at any time without losing services. McLeod also suggests that clients be given the name and contact information of an outside arbiter in the event they want to withdraw but are uncomfortable alerting their service providers because of their affiliations with the research. 
Another ethical consideration that is somewhat unique to action research is participant confidentiality. Often action research, especially outcome based evaluation, is conducted using the same standards to protect participant identity that are used in standard research studies. However, there are other cases, particularly when conducting PAR, when action researchers may chose to disclose the names of the participants and/or the site in which the data were collected. For example, community members participating in PAR may prefer that their real names be used in the reporting of the research so that they can be available to facilitate the process of social change. In their manual for the protection of human subjects, McGuire Dunn and Chadwick (2004) note that in these cases, "identification may be done by attribution of direct quotes citing ideas, in the description of the activities, and/or in the explanations of the research collaborative" (p. 109). Any time participant identifying information is disclosed, action researchers need to carefully discuss with the participants and, when appropriate, the local human subjects review board office, the potential ramifications of their disclosures. Bogdan and Biklen (2007) note that action researchers may also chose to report the sites where the data were collected when conducting research aimed at uncovering injustices by a particular group or organization (e.g., the mistreatment of patients in psychiatric facilities or nursing homes). In these cases, the authors caution action researchers to implement procedures to make sure that their data are accurate and to carefully consider with stakeholders the personal or legal repercussions of any public disclosures of wrong-doing.

\section{Step 3: Data Collection and Analysis}

Data collection procedures used in action research vary greatly depending upon the nature of the study and can include interviews, client self-report surveys or questionnaires, external observations of counseling sessions, and analyses of client records. One key 
consideration in collecting data for action research is that data should be collected in ways that enhance rather than impede the lives of the participants. For example, when conducting an evaluation of a therapeutic intervention, it can be helpful to the therapeutic process if data are collected in a manner that facilitates client reflection regarding the therapeutic process. Conversely, it could be harmful to the therapeutic process to ask clients to complete questionnaires that may appear unrelated to their sessions or that take up lengthy amounts of session or personal time. Action researchers should also allow participants to comment on the data collection process to make sure that it is not distracting them from their goals and build in opportunities to adjust the procedures when needed.

Analyzing data can be one of the most complicated aspects of the research study. There are numerous guides available for assisting researchers in analyzing qualitative (e.g., Bogdan \& Biklen, 2007; Corbin \& Strauss, 2008) and quantitative (e.g., Tabachnik \& Fidell, 2007) data using rigorous methods. Due to the complexity of analytic procedures and software (both quantitative and qualitative), it is useful to have experienced researchers, whenever possible, involved in this aspect of the analytic process to assist practitioners in analyzing the data and understanding the results.

When analyzing qualitative data, it is crucial for action researchers to employ methods that assist them in becoming aware of their own biases and how these biases could shape their interpretations of the data. Although biases can affect the results of all research, the more inductive forms of qualitative research such as grounded theory (Corbin \& Strauss, 2008) are especially informed by the social positioning of the researcher(s). Action researchers who utilize qualitative approaches need to integrate standard procedures used to ensure trustworthiness of 
the data, which include use of memos, peer-debriefing groups, member-checking, and the active search for negative case data (see Bogdan \& Biklen, 2007).

Action researchers utilizing quantitative methods are often limited in their abilities to utilize traditional procedures such as correlation and regression because of small sample sizes. The need for large sample sizes can be addressed in various ways, but one innovative solution is to make use of emerging technologies that have made more elegant research designs, such as multilevel modeling, more accessible. Of these, Experience Sampling Methodology (ESM) offers particular promise for the action researcher. A detailed discussion of ESM is beyond the scope of the present paper (readers are referred to Christensen, Feldman-Barrett, Bliss-Moreau, Lebo, \& Kaschub, 2003; Feldman-Barrett \& Barrett, 2001) but in brief, ESM allows the researcher to collect large amounts of data from a limited number of participants (e.g., 20-30). Typically, ESM involves the use of handheld palm pilots on which brief surveys have been recorded and which participants agree to carry with them for a specified time. This approach has several advantages. First, data collected in this way allow the researcher to conduct what amounts to a small-scale longitudinal study, since participants are followed over time. Second, they allow the researcher to move beyond the traditional exploration of between-person differences and to explore within-person associations among variables of interest (e.g., how wellbeing fluctuates within individual participants during the course of their day, in response to identified daily life events). Third, by collecting such data in participants’ daily, real-world settings rather than in the lab, such studies demonstrate increased ecological validity, an oftencited weakness of traditional lab-based designs. We know of no studies to date that have employed ESM specifically to investigate counseling processes, but the possibilities are numerous. 


\section{Step 4: Presenting Results}

Often the results of action research are shared only among the researchers and participants themselves. Although the focus is always on the setting in which the research was conducted, results can also be useful to other practitioners working in similar settings. Therefore, action researchers are encouraged to consider writing their study results and submitting them for publication. Many ACA journals, including the Journal of Counseling \& Development, have special sections devoted to disseminating practitioner-based research.

Although action-research articles should follow the same basic format as other research articles, there are some special considerations that action researchers should attend to when preparing their manuscripts. Like most articles, the authors should begin by providing a solid rationale regarding the need for the study, which includes a critical review of the literature in this area and highlight the gap this research is fulfilling. However, the action research article should also include a description of the collaboration that occurred between all of the members of the research team. Additionally, action research articles need to include more contextual, sitespecific information regarding the need for the study than standard research articles, including specific information about the clients, counselors, and researchers. This type of information not only enforces the need for the study, but also assists other practitioners in translating the material to their own settings. According to Stringer (2007), it is also important that action researchers summarize all of the stakeholder's accounts of the research process and findings, including those that may differ from the perspectives held by the majority of the research team.

Another key component of action-research articles is that authors include detailed descriptions of the interventions that were used. This is especially important when the focus of the research is to test the efficacy of a new intervention with a particular population. Authors 
should provide specific details about each stage of the intervention and who provided the intervention, including the training that each service provider received, so that other practitioners are able to replicate the intervention in supplementary settings. Additionally, authors of action research articles need to address how they attended to the various ethical dilemmas unique to this form of counseling research (detailed earlier in this article) and the steps taken to ensure treatment uniformity (if applicable). Like other research articles, appropriate details about data collection and analysis procedures should be provided, although more attention is needed in explaining the positionality of the researchers and the methods employed to assist in addressing potential researcher biases. When reporting results, authors of action research articles should carefully delineate the significance of the research in shaping their own practice along with the potential implications of the work to other practitioners and researchers without overstating the findings. According to Stringer (2007) action researchers can also include in their reports the proposed next steps and timelines for accomplishing the changes or advocacy procedures that emerged from the findings.

\section{Summary}

Action research has the potential to advance the field of counseling by creating a pathway for resolving the long standing disconnect between research and practice within our profession. The results of action research are relevant to practitioners and easily translated into practice because the questions that action researchers pose are generated by the practitioners themselves. In addition, counseling practitioners are advantaged as action researchers because the requisite skills and values that inform quality action research, including creativity, reflexivity, the ethics of relationship power differentials, and advocacy for vulnerable clients, are central features of our clinical training. Action research, therefore, provides potential for counselors to produce a body 
of literature that is tailored to the unique needs of counselors and is consistent with our developmental, ecological, multicultural, and advocacy-based traditions

In this article we have presented a number of special considerations for conducting and reporting action research that distinguish this mode of inquiry from other research traditions. Most notably, action researchers need to work closely with practitioners to not only identify problems that are relevant to the field, but to also partner with practicing counselors and/or clients throughout the research process. Other considerations outlined in this paper include addressing ethical issues such as counselor/researcher dual roles, participant confidentiality, techniques for collecting data that neither disrupt client process nor disturb general functioning at the site where the research is conducted, and focusing on results that empower or improve the lives of the participants. This view of practitioner research suggests a radical vision for producing a uniquely counseling body of literature to guide the profession and future scholarly effort—one that is first and foremost guided by the interests of those served by the profession. Thus, action researchers who adhere to the guidelines delineated in this article and publish their work in ACA journals such as JCD have the potential to advance the field with research that is both rigorous and uniquely relevant to counselors and clients.

\section{References}

Adelman, C. (1993). Kurt Lewin and the origins of action research. Educational Action Research, 1, 7-24. doi:10.1080/0965079930010102

Bauman, S. (2002). School counselors' interest in professional literature and research. Professional School Counseling, 5, 346-352. 
Bogdan, R.C., \& Biklen, S.K. (2007). Qualitative research in education: An introduction to theory and methods. Needham Heights, MA: Allyn \& Bacon.

Christensen, T.C., Feldman-Barrett, L., Bliss-Moreau, E., Lebo, K., \& Kaschub, C. (2003). A practical guide to experience sampling procedures. Journal of Happiness Studies, 4, 53-78. doi:10.1023/A:1023609306024

Corbin, J., \& Strauss, A. (2008). Basics of qualitative research. Thousand Oaks, CA: Sage.

Feldman-Barrett, L., \& Barrett, D. (2001). An introduction to computerized experience sampling in psychology. Social Science Computer Review, 19, 175-185.

doi: $10.1177 / 089443930101900204$

Goldman, L. (1976). A revolution in counseling research. Journal of Counseling Psychology, 23, 543-552. doi:10.1037/0022-0167.23.6.543

Guiffrida, D.A., \& Douthit, K.Z. (2010). Perspectives on the state of counselor education research: A response to Kaplan’s “A radical thought on counseling research: Let’s stop doing it. Spectrum, 70 (2), 22-24.

Heppner, P.P., \& Anderson, W.P. (1985). On the perceived non-utility of research in counseling. Journal of Counseling \& Development, 63, 545-547.

Herr, K., \& Anderson, G.L. (2005). The Action Research Dissertation: A Guide for Students and Faculty. Thousand Oaks, CA: Sage. 
Howard, G.S. (1984). A modest proposal for a revision of strategies for counseling research. Journal of Counseling Psychology, 31,430-441. doi:10.1037/0022-0167.31.4.430

Kaplan, D. (2010). A radical thought on counseling research: Let's stop doing it. ACES Spectrum, 70 (1), 25-26.

Kidd, S.A., \& Kral, M.J. (2005). Practicing participatory action research. Journal of Counseling Psychology, 52, 187-195. doi: 10.1037/0022-0167.52.2.187

King, J.H., \& Otis, H. Gray. (2004). Bridging the research-practice gap: Using applied inquires to promote client advocacy. In G.R. Walz \& R. Yep (Eds.), VISTAS- Perspectives on Counseling 2004 (pp. 259-269). Alexandria, VA: American Counseling Association.

Lundervold, D.A., \& Belwood, M.F. (2000). The best kept secret in counseling: Single-case (N=1) experimental designs. Journal of Counseling \& Development, 78, 92-102.

McLeod, J. (1999). Practitioner Research in Counseling. London: Sage.

McGuire Dunn, C., \& Chadwick, G.L. (2004). Protecting Study Volunteers in Research. Boston, MA: Thompson.

Rowell, L.L. (2005). Collaborative action research and school counselors. Professional School Counseling, 9 28-36.

Rowell, L.L. (2006). Action research and school counseling: Closing the gap between research and practice. Professional School Counseling, 9, 376-384.

Schon, D.A. (1995). The new scholarship requires a new epistemology. Change, 27, 27-34.

Stringer, E. (2007). Action Research in Education. Upper Saddle River, NJ: Sage. 
Tabachnik, B. G., \& Fidell, L. S. (2007). Using Multivariate Statistics, $5^{\text {th }}$ ed. Boston:

Allyn \& Bacon.

Thorne, S. (2008). Interpretive Description: Developing Qualitative Inquiry. Walnut Creek, CA: Left Coast Press.

Whiston, S.C. (1996). Accountability through action research: Research methods for practitioners. Journal of Counseling \& Development, 74, 616-623. 